\title{
O CERRADÃO DE GOIÁS E SUAS RELAÇÕES FLORÍSTICAS E ESTRUTURAIS COM OUTRAS ÁREAS NO BRASIL
}

Sabrina do Couto de Miranda ${ }^{1}$; Weuler Alves Vasconcelos ${ }^{2}$; Cassio Henrique Giusti Cezare 3; Cristiane Ribeiro da Mata ${ }^{4}$; Kharen Santana Fonseca ${ }^{4}$.

${ }^{1}$ Professora de Botânica. Universidade Estadual de Goiás, Campus Palmeiras de Goiás (Bolsista do Programa BIP-UEG). E-mail: sabrinac.miranda@gmail.com ${ }^{2}$ Acadêmico do Curso de Pós-Graduação Lato Sensu em Manejo e Conservação dos

Ecossistemas Naturais e Sistemas Agrários. Universidade Estadual de Goiás,

Campus Palmeiras de Goiás.

${ }^{3}$ Doutorando do Curso de Pós-Graduação Stricto Sensu em Ciências Ambientais da Universidade Federal de Goiás, Goiânia, Goiás.

${ }^{4}$ Graduanda em Agronomia na Universidade Estadual de Goiás, Campus Palmeiras de Goiás.

Recebido em: 02/10/2017 - Aprovado em: 21/11/2017 - Publicado em: 05/12/2017 DOI: 10.18677/EnciBio_2017B89

\begin{abstract}
RESUMO
O cerradão apresenta espécies vegetais comuns com o cerrado sentido restrito e as formações florestais de Cerrado. Trata-se de uma das fitofisionomias menos conhecidas do bioma. Este trabalho objetivou analisar os aspectos florísticos e estruturais de um remanescente de cerradão em Goiás, assim como, suas relações com outras áreas amostradas em diferentes localidades no Brasil. Foram calculados os índices de Sørensen, Czekanowski e TWINSPAN. No fragmento de cerradão localizado em Itapirapuã-GO foram amostrados todos os indivíduos lenhosos com $\mathrm{Db} \geq 5 \mathrm{~cm}$ em 10 parcelas de $1.000 \mathrm{~m}^{2}$. Os dados de campo foram comparados com dados levantados na literatura que incluem cerradões no DF (2 áreas), SP (2), MG (5), MT (1) e MA (1). Para efeito de comparação foram excluídas das análises espécies identificadas até gênero e espécies que ocorreram em apenas uma das áreas. O Sørensen mostrou que as áreas mais similares são as de Brasília-DF (áreas 1 e 8) e as mais dissimilares estão localizadas no MT e MA (Áreas 3 e 11). 0 cerradão amostrado neste estudo (Área 12) apresentou similaridade florística de 0,50 com o grupo das áreas 4 e 6, ambas em MG. O Czekanowski mostrou agrupamentos semelhantes ao Sørensen, contudo os aspectos estruturais diferenciaram ainda mais as áreas entre si. O TWINSPAN indicou que o cerradão localizado em Goiás (área 12) possui proximidade florística com as áreas de Curvelo e Araguari (MG), corroborando o Sørensen. As análises comparativas sugerem que fatores biogeográficos e históricos podem influenciar a composição florística.
\end{abstract}

PALAVRAS-CHAVE: Análises multivariadas, Cerrado, Estrutura. 


\title{
THE "CERRADÃO” OF GOIÁS AND IT'S FLORISTIC AND STRUCTURAL RELATIONSHIP WITH OTHER AREAS IN BRAZIL
}

\begin{abstract}
The cerradão presents common plant species with the cerrado sensu stricto and the forest formations of Cerrado. It is one of the least known phytophysiognomies of the biome. This work aimed to analyze the floristic and structural aspects of a remnant of cerradão in Goiás, as well as its relationships with other areas sampled in different localities in Brazil. The Sørensen, Czekanowski and TWINSPAN indices were calculated. In the cerradão fragment located in Itapirapuã-GO, all the woody individuals with diameter of base $(\mathrm{Db}) \geq 5 \mathrm{~cm}$ were sampled in 10 plots of $1,000 \mathrm{~m}^{2}$. Field data were compared with data collected in the literature that include cerradões in states of DF (2 areas), SP (2), MG (5), MT (1) and MA (1). For comparison purposes, species identified to genus and species that occurred in only one area were excluded from the analyzes. Sørensen showed that the most similar areas are Brasilia-DF (areas 1 and 8) and the most dissimilar are located in the MT and MA (Areas 3 and 11). The cerradão sampled in this study (Area 12) presented floristic similarity of 0.50 with the group of areas 4 and 6, both in MG state. Czekanowski showed groupings similar to Sørensen, but the structural aspects further differentiated the areas from each other. TWINSPAN showed that the cerradão located in Goiás (area 12) has floristic proximity to the areas of Curvelo and Araguari (MG), corroborating the Sørensen. Comparative analyzes suggest that biogeographic and historical factors can influence composition.
\end{abstract}

KEYWORDS: Cerrado, Multivariate analyzes, Structure.

\section{INTRODUÇÃO}

O Cerrado ocupa uma área de cerca de $2.036 .448 \mathrm{~km}^{2}$ (23,9\% do país) e limita-se com quase todos os biomas brasileiros, a exceção do Pampa (Campos Sulinos) (IBGE, 2004). Dentre as savanas tropicais mundiais, o Cerrado se destaca em riqueza e diversidade de espécies (KLINK; MACHADO, 2005). Para a flora vascular já foram catalogadas mais de 11.000 espécies (MENDONÇA et al., 2008) e este ecossistema apresenta o segundo maior número de endemismos de plantas com sementes (4.151 espécies), atrás da Floresta Atlântica (FORZZA et al., 2010).

A grande diversidade de espécies no Cerrado está associada a diversidade de ambientes. Enquanto a estratificação vertical da Floresta Amazônica ou da Floresta Atlântica proporciona oportunidades diversas para o estabelecimento das espécies, no Cerrado a heterogeneidade espacial seria um fator determinante para a ocorrência de um variado número de espécies (MACHADO et al., 2004).

Uma característica marcante do Cerrado é a paisagem em mosaicos e a alta diversidade de formações vegetacionais. A vegetação de Cerrado pode ser agrupada em três tipos de formações: campestres, com predomínio de plantas herbáceas; savânicas, com a presença de dois estratos distintos, rasteiro (subarbustivoherbáceo) e lenhoso (arbustivo-arbóreo); e florestais, com vegetação predominantemente arbórea e formação de dossel fechado (RIBEIRO; WALTER, 2008). De modo geral, os subtipos variam de acordo com fatores fisiográficos, ou ainda em função da altura do lençol freático, do tipo de drenagem ou da profundidade da camada de solo disponível ao estabelecimento das plantas (RIBEIRO; WALTER, 2008).

Estudo publicado por Miranda et al. (2014) mostrou que o Cerrado apresenta gradiente de aumento de biomassa aérea lenhosa que varia das formações 
campestres para as florestais. Estas últimas são extremamente importantes para o estoque de carbono na porção aérea da vegetação. Estes autores ainda comentam que para o Cerrado são extremamente importantes estudos com metodologia padronizada, visando assim diminuir as incertezas nas estimativas. Além disso, diante da grande extensão geográfica do Cerrado e da intensa pressão antrópica a qual o ecossistema está submetido, as mudanças de uso da terra podem alterar a dinâmica regional de carbono e, consequentemente, de outros gases de efeito estufa (CASTRO; KAUFFMAN, 1998; MIRANDA et al., 2014).

Dentre as fitofisionomias do Cerrado, o cerradão se enquadra nas formações florestais do bioma. Fisionomicamente é uma floresta, porém do ponto de vista florístico assemelha-se com o cerrado sentido restrito. Apresenta dossel contínuo e cobertura arbórea entre $50 \%$ e $90 \%$. Esta variação na cobertura influencia nas condições de luminosidade favorecendo diferenciação nos estratos arbustivo e herbáceo (RIBEIRO; WALTER, 2008). Conforme mencionado, é uma fitofisionomia importante em termos de estoque de carbono na porção aérea da biomassa. Portanto, são necessários estudos em áreas de Cerradão.

Neste contexto, este trabalho teve por objetivos analisar os aspectos florísticos e estruturais de um remanescente de cerradão em Goiás, bem como, suas relações com outras áreas de cerradão amostradas em diferentes localidades no Brasil.

\section{MATERIAL E MÉTODOS}

O remanescente de cerradão localizado no município de Itapirapuã, Goiás, foi amostrado utilizando 10 parcelas de $20 \times 50 \mathrm{~m}$, ou seja, um hectare no total. Estabeleceu-se como critério mínimo a inclusão de indivíduos lenhosos com diâmetro da base (Db), medido a $30 \mathrm{~cm}$ do solo, $\geq 5 \mathrm{~cm}$, exceto lianas, palmeiras e veloziáceas. Os indivíduos incluídos na amostragem tiveram, além dos diâmetros, também as alturas mensuradas. A altura total foi considerada como a projeção vertical da base do tronco até o ramo mais alto ou folhagem. Para a mensuração do diâmetro utilizou-se uma suta de alumínio e para a altura vara graduada em metros.

Os parâmetros densidade, frequência e dominância (absolutas e relativas), e o índice de valor de importância (IVI) (MÜELLER-DOMBOIS; ELLENBERG, 1974) foram calculados no programa Excel. A classificação das famílias botânicas seguiu o sistema do Angiosperm Phylogeny Group III (APG III, 2009) e os nomes científicos das espécies foram conferidos por meio de consultas ao "W3 Tropicos". A identificação foi feita in loco e para as espécies não identificadas no momento da mensuração foram coletadas amostras para posterior identificação em herbário e/ou consultas a especialistas.

A diversidade florística foi analisada com base nos valores de riqueza e nos índices de diversidade de Shannon e Wiener e Uniformidade de Pielou (MAGURRAN; MCGILL, 2011), calculados através do programa MVSP (KOVACH, 1993).

Dados sobre composição florística e estrutura para a fitofisionomia cerradão foram levantados na literatura. Selecionou-se trabalhos recentes que utilizaram coletas em campo. A partir deste levantamento foram analisados dados para outras 11 áreas de cerradão no Brasil (Tabela 1). Para não comprometer as comparações florísticas entre as áreas foram excluídas das análises espécies identificadas até gênero, bem como, a categoria "mortas ou mortas em pé". Além disso, Byrsonima versicolor (Área 8) e Tapirira elaegnoides (Área 2), foram excluídas, pois tais nomes científicos não foram encontrados como válidos na base consultada. 
QUADRO 1. Localidades com estudos florísticos e fitossociológicos em áreas de cerradão no Brasil.

\begin{tabular}{lcc}
\hline \multicolumn{1}{c}{ Localidade/Estado } & Referências & Área/Código \\
\hline Jardim Botânico de Brasília - DF & Caseiro, 2013 & Área 01 \\
Pirassununga - SP & Fina e Monteiro, 2009 & Área 02 \\
Paconé - MT & Moretti et al., 2013 & Área 03 \\
Curvelo - MG & Otoni et al., 2013 & Área 04 \\
Assis - SP & Pinheiro e Durigan, 2012 & Área 05 \\
Araguari - MG & Rodrigues e Araújo, 2013 & Área 06 \\
Uberlândia - MG & Rodrigues e Araújo, 2013 & Área 07 \\
Lago Sul - DF & Silva, 2009 & Área 08 \\
Distrito Industrial Uberlândia - MG & Alves et al., 2013 & Área 09 \\
Monte Carmelo - MG & Prado Júnior et al., 2012 & Área 10 \\
Urbano Santos - MA & Silva et al., 2008 & Área 11 \\
Itapirapuã - GO & Este estudo & Área 12 \\
\hline
\end{tabular}

A similaridade florística entre o remanescente de cerradão estudado e as outras áreas (Quadro 1) foi calculada através dos índices de Sørensen (MAGURRAN, 2004) e Czekanowski (KENT; COKER, 1992), calculados através do programa MVSP (KOVACH, 1993). Estes índices se baseiam, respectivamente, na presença de espécies e também nos valores de densidade. Para esta análise foram excluídas as espécies consideradas localmente raras, ou seja, aquelas com densidade de 1 ind.ha ${ }^{-1}$.

Padrões florísticos na distribuição das espécies nas comunidades foram investigados através da aplicação do método TWINSPAN (Two-Way Indicator Species Analysis) mediante o uso do programa PC-ORD (MCCUNE; MEFFORD, 2006). Este método classifica simultaneamente espécies/áreas e evidencia espécies indicadoras e preferenciais por meio de dicotomizações sucessivas (KENT; COKER, 1992). Os níveis de corte adotados foram 0, 2, 5, 10 e 20. A matriz elaborada contou com 180 espécies e 12 áreas, para a análise foram excluídas as espécies raras, ou seja, com 1 ind.ha ${ }^{-1}$ e/ou ocorrência em apenas uma área.

\section{RESULTADOS E DISCUSSÃO}

A caracterização geral das áreas analisadas foi sintetizada na tabela 1. $O$ método de amostragem predominante foi parcela e a maioria dos estudos amostrou 1 hectare de área no total (Tabela 1). Contudo, o critério de inclusão dos indivíduos lenhosos variou entre as áreas, o que influenciou nos valores de densidade encontrados (Tabela 1). De acordo com Miranda et al. (2014) são necessários métodos padronizados de amostragem para estudos florísticos e fitossociológicos realizados no Cerrado visando facilitar comparações e viabilizar a proposição de planos de manejo e recuperação de áreas degradadas. 
TABELA 1. Dados florístico-estruturais e caracterização das áreas de estudo quanto à metodologia de amostragem. Onde: $\mathrm{Db}=$ diâmetro da base; $\mathrm{PAP}=$ perímetro a altura do peito; $\mathrm{DAP}=$ diâmetro a altura do peito; $\mathrm{CAP}=$ circunferência a altura do peito.

\begin{tabular}{|c|c|c|c|c|c|c|c|c|}
\hline $\begin{array}{l}\text { Área/ } \\
\text { Código }\end{array}$ & $\begin{array}{l}\text { Método de } \\
\text { Amostragem }\end{array}$ & $\begin{array}{l}\text { Critério de } \\
\text { Inclusão }\end{array}$ & Tipo de solo & $\begin{array}{l}\text { Área } \\
\text { Amostral } \\
\text { (ha) }\end{array}$ & $\begin{array}{l}\text { Densidade } \\
\text { (ind/ha) }\end{array}$ & $\mathbf{H}^{\prime}$ & $\mathbf{J}^{\prime}$ & $\mathbf{S}$ \\
\hline Área 01 & $\begin{array}{l}\text { Parcelas } \\
(20 \times 50 \mathrm{~m})\end{array}$ & $\begin{array}{l}\mathrm{Db} 30 \mathrm{~cm} \\
\geq 5 \mathrm{~cm}\end{array}$ & $\begin{array}{l}\text { Latossolo Vermelho } \\
\text { e Amarelo }\end{array}$ & 1 & 2.412 & 3,55 & 0,76 & 99 \\
\hline Área 02 & $\begin{array}{l}\text { Parcelas } \\
(10 \times 10 \mathrm{~m})\end{array}$ & $\begin{array}{l}\text { PAP } \\
\geq 10 \mathrm{~cm}\end{array}$ & $\begin{array}{l}\text { Latossolo Vermelho } \\
\text { Escuro }\end{array}$ & 0,34 & 2.147 & 3,45 & 0,78 & 80 \\
\hline Área 03 & $\begin{array}{l}\text { Parcelas } \\
(10 \times 5 \mathrm{~m})\end{array}$ & $\begin{array}{l}\text { PAP } \\
\geq 10 \mathrm{~cm}\end{array}$ & $\begin{array}{l}\text { Latossolo Vermelho } \\
\text { Amarelo }\end{array}$ & 0,04 & 2.150 & 2,13 & 0,81 & 14 \\
\hline Área 04 & $\begin{array}{l}\text { Parcelas } \\
(20 \times 50 \mathrm{~m})\end{array}$ & $\begin{array}{l}\mathrm{Db} 30 \mathrm{~cm} \\
\geq 5 \mathrm{~cm}\end{array}$ & Solo distrófico & 1 & 2.424 & $3,52^{*}$ & $0,79^{*}$ & 92 \\
\hline Área 05 & $\begin{array}{l}\text { Parcelas } \\
(20 \times 50 \mathrm{~m})\end{array}$ & $\begin{array}{l}\text { DAP } \\
\geq 5 \mathrm{~cm}\end{array}$ & Latossolo Vermelho & 1 & 1.779 & 3,19 & $0,75^{\star}$ & 71 \\
\hline Área 06 & $\begin{array}{l}\text { Parcelas } \\
(20 \times 20 \mathrm{~m})\end{array}$ & $\begin{array}{l}\text { CAP } \\
\geq 15 \mathrm{~cm}\end{array}$ & Cambissolo & 1 & 1.340 & 3,50 & $0,78^{*}$ & 83 \\
\hline Área 07 & $\begin{array}{l}\text { Parcelas } \\
(20 \times 20 \mathrm{~m})\end{array}$ & $\begin{array}{l}\text { CAP } \\
\geq 15 \mathrm{~cm}\end{array}$ & Latossolo Vermelho & 1 & 1.797 & 3,20 & $0,73^{*}$ & 78 \\
\hline Área 08 & $\begin{array}{l}\text { Parcelas } \\
(20 \times 50 \mathrm{~m})\end{array}$ & $\begin{array}{l}\mathrm{Db} 30 \mathrm{~cm} \\
\geq 5 \mathrm{~cm}\end{array}$ & Latossolo Vermelho & 1 & 1.458 & 3,85 & 0,82 & 107 \\
\hline Área 09 & $\begin{array}{l}\text { Parcelas } \\
(20 \times 20 \mathrm{~m})\end{array}$ & $\begin{array}{l}\text { CAP } \\
\geq 15 \mathrm{~cm}\end{array}$ & $\begin{array}{l}\text { Latossolo Vermelho } \\
\text { Escuro }\end{array}$ & 1 & 1.353 & 3,46 & $0,79^{*}$ & 74 \\
\hline Área 10 & Ponto Quadrante & $\begin{array}{l}\text { DAP } \\
\geq 5 \mathrm{~cm}\end{array}$ & $\begin{array}{l}\text { Latossolo vermelho } \\
\text { escuro e Latossolo } \\
\text { roxo }\end{array}$ & $\begin{array}{l}2 \\
\text { transectos } \\
\text { de } 500 \mathrm{~m}\end{array}$ & 1.665 & 3,03 & 0,76 & 55 \\
\hline Área 11 & Ponto Quadrante & $\begin{array}{l}\text { DAS } \\
\geq 1 \mathrm{~cm}\end{array}$ & 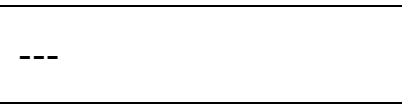 & 0,572 & 2.780 & 3,31 & 0,78 & 69 \\
\hline $\begin{array}{l}\text { Área } 12 \\
\text { (Este estudo) }\end{array}$ & $\begin{array}{l}\text { Parcelas } \\
(20 \times 50 \mathrm{~m})\end{array}$ & $\begin{array}{l}\mathrm{Db} 30 \mathrm{~cm} \\
\geq 5 \mathrm{~cm}\end{array}$ & Cambissolo & 1 & 1.699 & 4,00 & 0,83 & 128 \\
\hline
\end{tabular}

* Valores não informados no trabalho, porém estimados a partir da tabela comparativa. 
$\mathrm{Na}$ área de cerradão localizada em Itapirapuã-GO foram amostrados 1.699 ind.ha ${ }^{-1}$ (Tabela 1), distribuídos em 128 espécies, 78 gêneros e 41 famílias. O valor de riqueza ficou dentro da faixa de variação encontrada para as demais áreas comparadas, entre 1.340 ind.ha $^{-1}$ e 2.780 ind.ha $^{-1}$ (Figura 1, Tabela 1). O menor valor de riqueza foi encontrado no cerradão amostrado em Poconé-MT (Area 3) e os maiores valores, acima de 100 espécies, foram encontrados nos cerradões amostrados no Lago Sul (Brasília-DF) (Área 8) e em Itapirapuã-GO (Área 12) (Tabela 1). Com relação aos índices de diversidade, de modo geral as áreas apresentaram alta equitabilidade, acima de $73 \%$, com base na Uniformidade de Pielou (Tabela 1). Os valores do índice de Shannon e Wiener foram altos, acima de 3 nats.ind ${ }^{-1}$, exceção ocorreu no cerradão amostrado em Poconé-MT (Área 03) que o baixo valor de riqueza influenciou no índice calculado, 2,13 nats.ind ${ }^{-1}$ (Tabela 1).

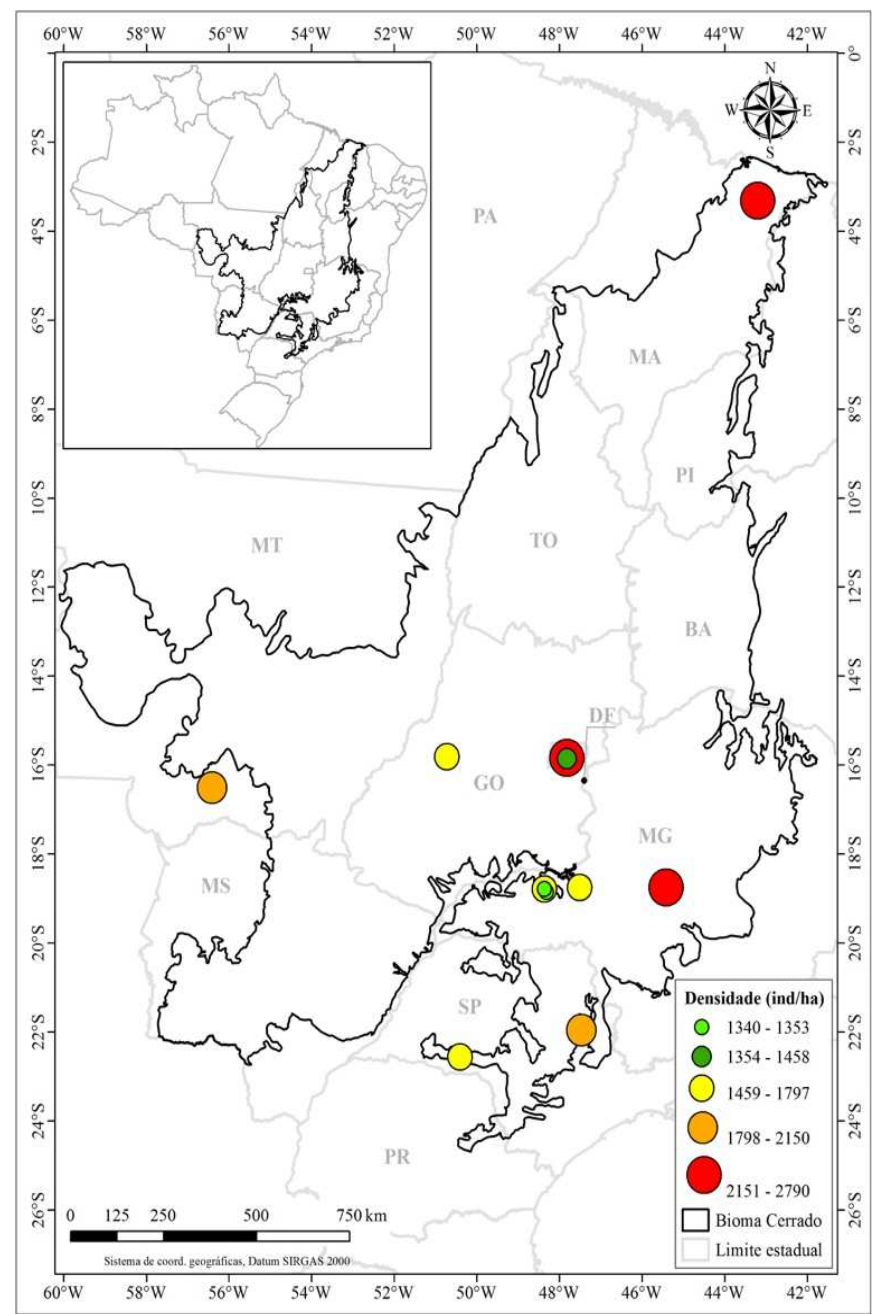

FIGURA 1: Distribuição geográfica das áreas de cerradão com estudos florísticos e fitossociológicos. O tamanho proporcional dos círculos reflete os valores de densidade absoluta. Fonte: Próprio autor.

De modo geral, os dados mostraram que a fitofisionomia cerradão apresenta alta riqueza, média de 79 espécies e coeficiente de variação (CV) $35,65 \%$, e diversidade de espécies, média de 3,35 nats.ind $^{-1}(C V=14,02 \%)$. Os altos valores de 
densidade (média=1.917 ind.ha ${ }^{-1}$ e $C V=24,16 \%$ ) corroboram o aspecto florestal desta fitofisionomia (RIBEIRO; WALTER, 2008).

Nas 12 áreas de cerradão comparadas (Figura 1) foram encontradas 344 espécies, a maioria ocorreu em apenas uma área (48,5\% do total), portanto podem ser consideradas localmente raras. Não foram encontradas espécies com ocorrência nas 12 áreas comparadas, apenas Bowdichia virgilioides Kunth e Plathymenia reticulata Benth. ocorreram em 10 das 12 áreas, portanto podem ser consideradas as espécies mais amplamente distribuídas no cerradão.

Para a análise de Sørensen considera-se alta similaridade para valores acima de 0,5 (MIRANDA, 2012). Portanto, os cerradões mais similares floristicamente estão localizados em Brasília-DF (Áreas 1 e 8) com valor 0,70 (Figura 2A). Em seguida tem-se os cerradões localizados em Uberlândia-MG (Áreas 7 e 9) com valor 0,65 (Figura 2A) e as áreas amostradas em Curvelo (Área 4) e Araguari (Área 6), ambas em Minas Gerais, com valor 0,54 (Figura 2A). O cerradão amostrado neste estudo (Área 12) apresentou similaridade florística de 0,50 com o grupo constituído pelas áreas 4 e 6 (Figura 2A), Curvelo e Araguari, respectivamente. As áreas 3 e 11 foram as mais dissimilares em comparação às demais, com valores de 0,05 e 0,15, respectivamente (Figura $2 \mathrm{~A}$ ).

$\mathrm{Na}$ análise de Czekanowski os valores são apresentados em percentual, sendo considerados elevados aqueles acima de 50\%. Neste sentido a similaridade estrutural entre todas as áreas foi baixa, pois não ocorreram valores acima de $50 \%$ (Figura 2B). Contudo, os grupos mais próximos continuam sendo aqueles constituídos pelas áreas de Brasília-DF (Áreas 1 e 8) e de Uberlândia-MG (Áreas 7 e 9), 47,9\% e 43,9\% de similaridade, respectivamente (Figura 2B). Do ponto de vista estrutural, o cerradão de Itapirapuã-GO (Área 12) apresentou 28,7\% de similaridade com os cerradões amostrados em Brasília-DF (Áreas 1 e 8) (Figura 2B).

Além disso, corroborando Sørensen, as áreas 3 e 11 foram as mais dissimilares, $1,73 \%$ e $5 \%$, respectivamente (Figura 2B), tal resultado pode estar relacionado ao fato de serem áreas disjuntas localizadas no Mato Grosso e Maranhão. É importante destacar que se percebeu, tanto no Sørensen quanto no Czekanowski, que o fator geográfico foi preponderante para a formação dos demais grupos (Figuras 2A e 2B).

Todas as divisões da classificação pelo TWINSPAN foram significativas, pois apresentaram autovalores $>0,30$ (FELFILI et al. 2007). A classificação corroborou que o cerradão de Poconé-MT (Área 3) é muito distinto dos demais (Figura 3), esta área se separou com autovalor 0,45 e nesta divisão foram elencadas duas espécies indicadoras $B$. virgilioides, que não foi amostrada em Poconé-MT, e Callisthene fasciculata Mart. com ocorrência em apenas duas áreas (Poconé-MT e Araguari$M G)$.

A segunda divisão separou as áreas 4, 6, 9, 11 e 12 das demais (autovalor 0,43) (Figura 3) e a espécie indicadora foi Agonandra brasiliensis Miers ex Benth. \& Hook. f., amostrada apenas nestas áreas. Posteriormente, houve a separação do cerradão localizado em Urbano Santos (Área 11) das demais áreas, autovalor 0,42 (Figura 3), a espécie indicadora foi Alibertia edulis (Rich.) A. Rich. ex DC., não amostrada na área 11. O cerradão amostrado em Itapirapuã-GO (Área 12) se separou dos demais com autovalor 0,38 (Figura 3) e a espécie indicadora foi Acosmium dasycarpum (Vogel) Yakovlev, neste conjunto de áreas a espécie ocorreu apenas em Itapirapuã-GO (Área 12). 
A

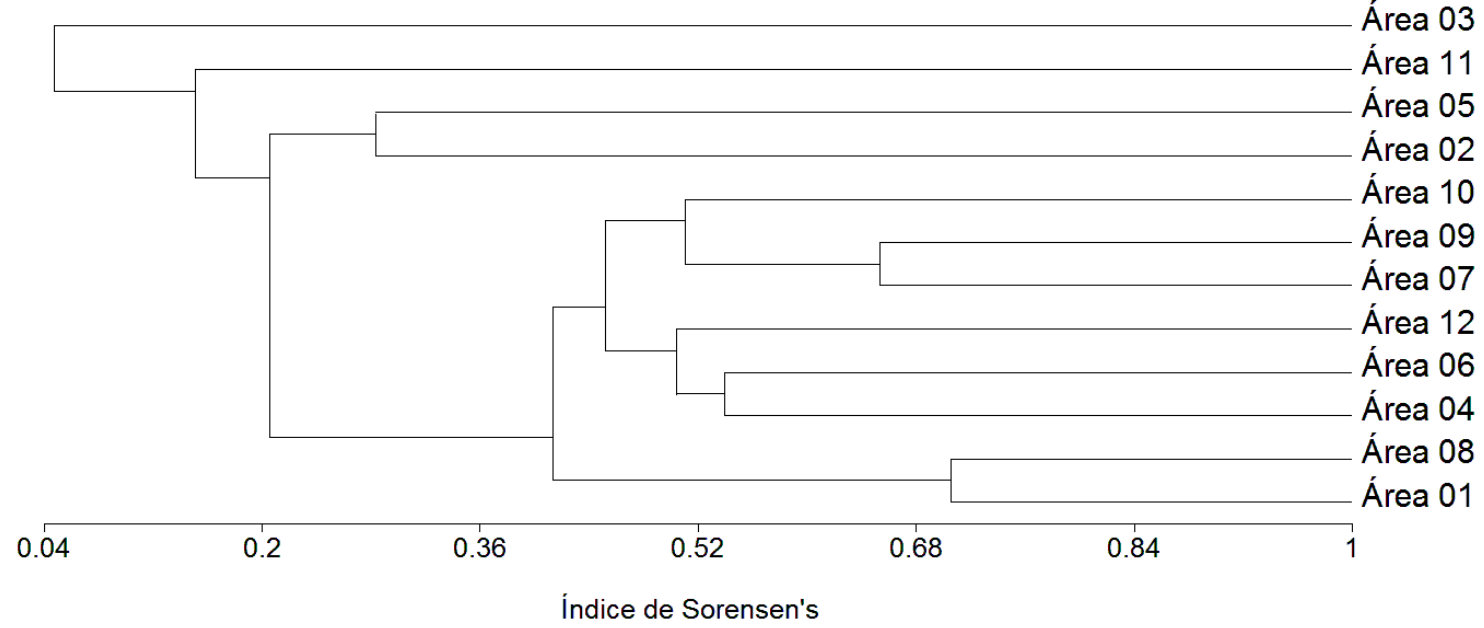

B

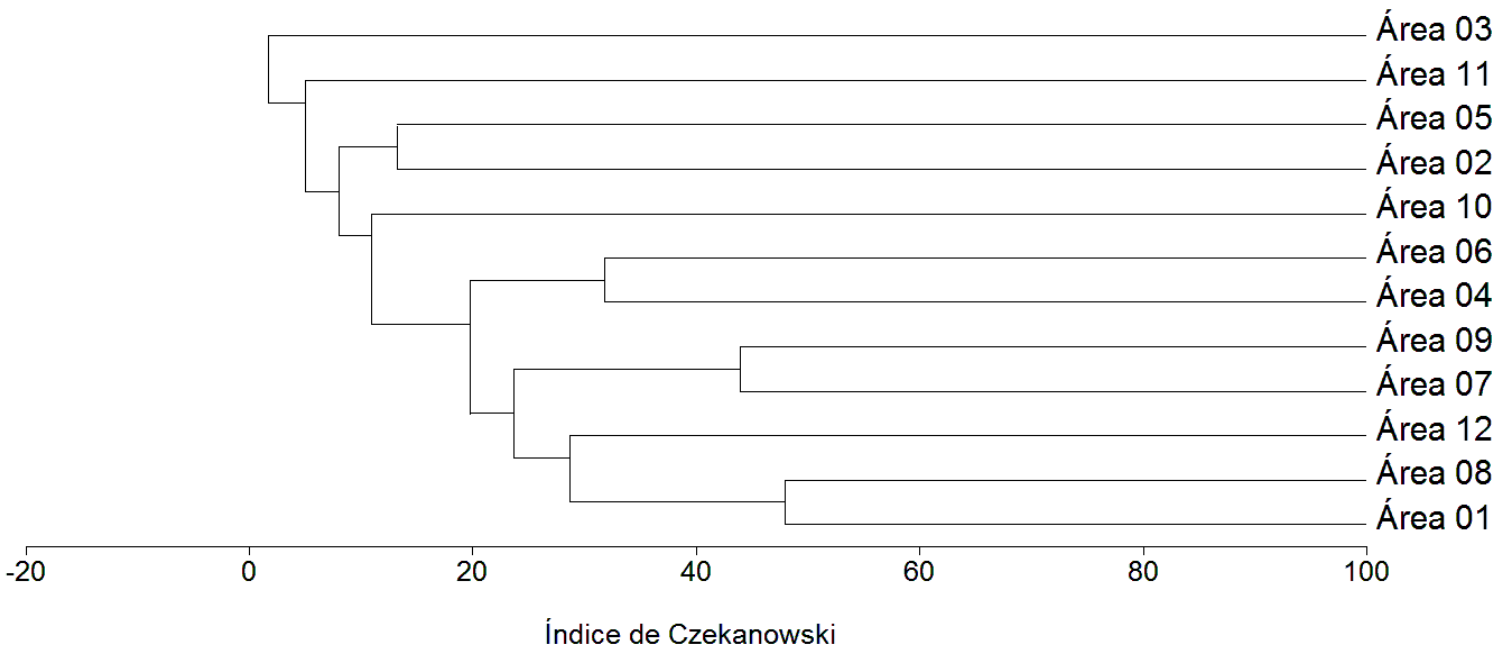

FIGURA 2: Dendrogramas de classificação da vegetação de cerradão produzidos a partir dos índices de Sørensen (A) e Czekanowski (B). Onde: Área 01=Jardim Botânico de Brasília, DF; Área 02=Pirassununga, SP; Área 03=Poconé, MT; Área 04=Curvelo, MG; Área 05=Assis, SP; Área 06=Araguari, MG; Área 07=Uberlândia, MG; Área 08=Lago Sul, DF; Área 09=Distrito Agroindustrial de Uberlândia, MG; Área 10=Monte Carmelo, MG; Área 11=Urbano Santos, MA; Área 12=Itapirapuã, GO. Fonte: Próprio autor.

No grupo da esquerda, composto por seis áreas de cerradão, a classificação separou as áreas 1 e 8, localizadas em Brasília-DF, das demais, autovalor 0,56 (Figura 3) e a espécie indicadora da divisão foi Antonia ovata Pohl, neste conjunto de áreas a espécie só ocorreu nas áreas 1 e 8. Posteriormente, foram formados dois grupos com duas áreas cada, áreas 5 e 10, e áreas 2 e 7 (Figura 3), com autovalor 0,46 e a espécie indicadora da divisão foi Acosmium subelegans (Mohlenbr.) Yakovlev. neste conjunto amostrado em Assis-SP (Área 5) e Monte Carmelo-MG (Área 10). 


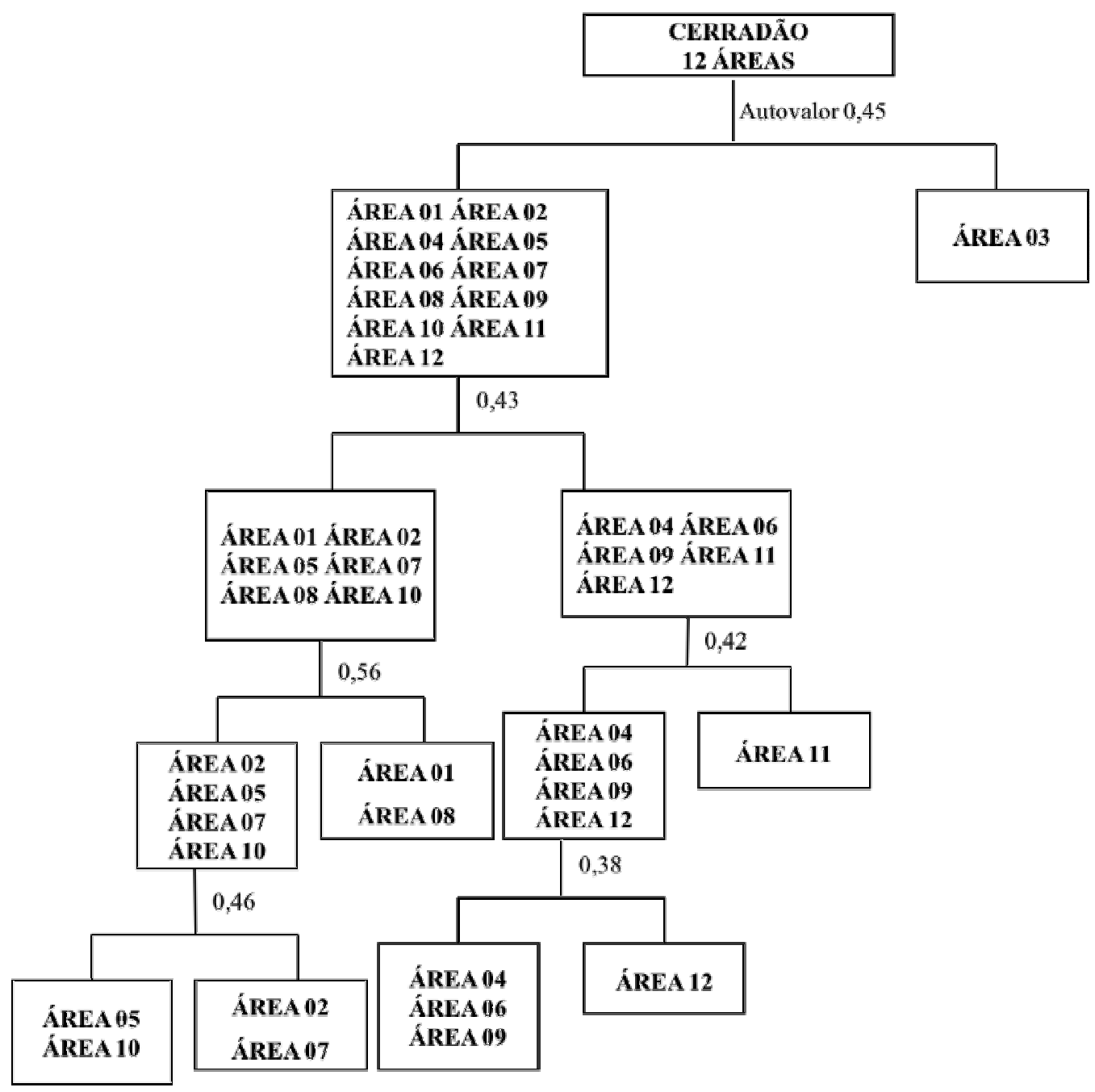

FIGURA 3: Classificação da vegetação lenhosa de áreas de cerradão pelo método TWINSPAN. Onde: Área 01=Jardim Botânico de Brasília, DF; Área 02=Pirassununga, SP; Área 03=Poconé, MT; Área 04=Curvelo, MG; Área 05=Assis, SP; Área 06=Araguari, MG; Área 07=Uberlândia, MG; Área 08=Lago Sul, DF; Área 09=Distrito Agroindustrial de Uberlândia, MG; Área 10=Monte Carmelo, MG; Área 11=Urbano Santos, MA; Área 12=Itapirapuã, GO. Fonte: Próprio autor.

O Sørensen e o TWINSPAN corroboraram que o cerradão localizado em Itapirapuã-GO (Área 12) possui proximidade florística com as áreas de Curvelo e Araguari, ambas em Minas Gerais. Apesar da distância geográfica estas áreas compartilham número relevante de espécies. Estas relações podem ser produto de fatores históricos e biogeográficos, sendo necessárias outras análises visando investigá-los.

As análises comparativas revelaram diferenciação florística e estrutural entre fragmentos localizados em um mesmo município. Tal fato destaca a complexidade associada à esta fitofisionomia e pode ser reflexo da influência, em escala local, de fatores como fertilidade e textura do solo, profundidade do lençol freático, frequência e intensidade do fogo, além de pressão por pisoteio pelo gado. Estes resultados 
destacam pontos importantes a serem investigados em estudos futuros.

\section{CONCLUSÃO}

A fitofisionomia cerradão apresenta alta riqueza e diversidade de espécies. Além disso, os altos valores de densidade corroboram que se trata de uma formação florestal do Cerrado. Observou-se diferenciação entre áreas com base na distribuição geográfica, confirmando a alta heterogeneidade espacial associada às fitofisionomias de Cerrado, o que dificulta, mas não inviabiliza, a proposição de planos de manejo e recuperação de áreas degradadas.

\section{AGRADECIMENTOS}

A primeira autora agradece o recurso financeiro concedido pelo $\mathrm{CNPq}$ via Edital Universal (14/2014). Também agradece à UEG pela bolsa via Pro-BIP (Programa de Concessão de Bolsa de Incentivo ao Pesquisador).

\section{REFERÊNCIAS}

ALVES, H. R.; PRADO JÚNIOR, J. A.; LOPES, S. F.; SILVA, P. P. F.; PEPPE, F. B.; SCHIAVINI, I. Fitossociologia e grupos ecológicos da comunidade lenhosa em um remanescente de cerradão em Uberlândia, MG. Caminhos de Geografia - Revista on line. v. 14, n. 46, p. 236-245, 2013.

APG III. An update of the Angiosperm Phylogeny Group classification for the orders and families of flowering plants: APG III. Botanical Journal of the Linnean Society 161: 105-121, 2009.

CASEIRO, R. A. O cerradão e o cerrado sentido restrito no Jardim Botânico de Brasília. Dissertação de Mestrado, Instituto de Ciências Biológicas, Universidade de Brasília, 2013.

CASTRO, E.; KAUFFMAN, J. Ecosystem structure in the Brazilian Cerrado: a vegetation gradient of aboveground biomass, root mass and consumption by fire. Journal of Tropical Ecology 14: 263-283, 1998.

FELFILI, J.M.; F.A. CARVALHO; LIBANO, A. M.; VENTUROLI, F.; PEREIRA, B. A. S. Análise multivariada em estudos de vegetação. Universidade de Brasília, Departamento de Engenharia Florestal. 60p, 2007.

FINA, B. G.; MONTEIRO, R. Estudo da estrutura da comunidade arbustivo-arbórea de uma área de cerradão, município de Pirassununga (SP). Neotropical Biology and Conservation, 4(1):40-48, 2009. Disponível em: <revistas.unisinos.br/index.php/neotropical/article/view/5114/2366>. Doi: $10.4013 / \mathrm{nbc} .2009 .41 .06$

FORZZA, R.C.; BAUMGRATZ, J. F.; BICUDO, C. E. M.; CANHOS, D. A. L.; CARVALHO-JÚNIOR, A. A.; et al. Síntese da diversidade brasileira. In: FORZZA, R.C. et al. (Eds.). Catálogo de Plantas e Fungos do Brasil. Rio de Janeiro vol. 1, p. 21-39, 2010.

IBGE - Instituto Brasileiro de Geografia e Estatística. Mapa de Biomas do Brasil: ENCICLOPÉDIA BIOSFERA, Centro Científico Conhecer - Goiânia, v.14 n.26; p. 1067 2017 
Primeira aproximação. Rio de Janeiro: IBGE, 2004.

KENT, M.; COKER, P. Vegetation description and analysis: a practical approach. Belhaven Press: London. 363p, 1992.

KLINK, C. A.; MACHADO, R. B. A conservação do Cerrado brasileiro. Megadiversidade 1(1): 147-155, 2005.

KOVACH, W. L. MVSP - Multivariate Statistical Package, version 3.1. Kovach Computing Services, Pentraeth, 1993.

MAGURRAN, A.E. Measuring biological diversity. Oxford: Blackwell Publishing. 256p, 2004.

MAGURRAN, A. E.; MCGILL, B. J. Biological Diversity: frontiers in measurement and assessment. Oxford University Press. 345p, 2011.

MACHADO, R. B.; RAMOS, M. B. N; PEREIRA, P. G.; CALDAS, E.; GONÇALVES, D. A.; et al. Estimativas de perda da área do Cerrado brasileiro. Relatório técnico não publicado. Brasília: Cl Brasil, 23 p, 2004.

MCCUNE, B.; MERRORD, M. J. PC-ORD. Multivariate Analysis of Ecological Data. Version 5.12. MjM Software, Gleneden Beach, Oregon, U.S.A, 2006.

MENDONÇA, R. C.; FELFILI, J. M.; WALTER, B. M. T.; SILVA JÚNIOR, M. C.; REZENDE, A. V.; et al. Flora vascular do Cerrado. In: SANO, S.M.; ALMEIDA, S. P.; RIBEIRO, J.F. (eds.). Cerrado: ecologia e flora. Embrapa Cerrados. Brasília-DF, 2008.

MIRANDA, S. C. Variação espacial e temporal da biomassa vegetal em áreas de Cerrado. Tese de Doutorado. Universidade de Brasília, Departamento de Ecologia. 143 p, 2012.

MIRANDA, S. C.; BUSTAMANTE, M.; PALACE, M.; HAGEN, S.; KELLER, M.; FERREIRA, L. G. Regional Variations in Biomass Distribution in Brazilian Savanna Woodland. Biotropica, 46(2), 125-138, 2014. Disponível em: $<$ https://www.researchgate.net/publication/260531715_Regional_Variations_in_Biom ass_Distribution_in_Brazilian_Savanna_Woodland>. Doi: 10.1111/btp.12095

MORETTI, M. S.; RIBEIRO, E. S.; CABRAL, R. S. O.; BARROS, L. S.; SOARES, G. $S$. Levantamento fitossociológico de mata de galeria e cerradão no município de Poconé, Mato Grosso. Revista Eletrônica Geoaraguaia. Barra do Garças-MT. Edição Especial. p. 193 - 208, 2013.

MÜLLER-DOMBOIS, D.; ELLENBERG, H. Aims and methods of vegetation ecology. New York: J. Wiley \& Sons. 574 p, 1974.

OTONI, T. J. O.; PEREIRA, I. M.; OLIVEIRA, M. L. R.; MACHADO, E. L. M.; FARNEZI, M. M.; MOTA, S. L. L. Componente arbóreo, estrutura fitossociológica e relações ambientais em um remanescente de cerradão, em Curvelo - MG. Revista 
Cerne, Lavras, v. 19, n. 2, p. 201-211, 2013. Disponível em: $<$ http://www.scielo.br/scielo.php?pid=S0104-

$77602013000200004 \&$ script=sci_abstract\&tlng=pt>.Doi:

http://dx.doi.org/10.1590/S0104-77602013000200004.

PRADO JÚNIOR, J. A.; LOPES, S. F.; VALE V.S.; DIAS NETO, O. C.; SCHIAVINI, I. Comparação florística, estrutural e ecológica da vegetação arbórea das fitofisionomias de um remanescente urbano de cerrado. Bioscience Journal, v.28, n.3, p.456-471, 2012.

PINHEIRO, E. S.; DURIGAN, G. Diferenças florísticas e estruturais entre fitofisionomias do cerrado em Assis, SP, Brasil. Revista Árvore, vol.36 no.1, 2012. Disponível em: <http://www.scielo.br/scielo.php?script=sci_arttext\&pid=S010067622012000100019>. Doi: http://dx.doi.org/10.1590/S0100-67622012000100019

RIBEIRO, J. F.; WALTER, B. M. T. As principais fitofisionomias do bioma Cerrado. In SANO, S. M.; ALMEIDA, S. P.; RIBEIRO, J. F. (Ed.). Cerrado: ecologia e flora. Embrapa Cerrados, Brasília-DF, pp. 153-212, 2008.

RODRIGUES, R. F.; ARAÚJO, G. M. Estrutura da vegetação e características edáficas de um cerradão em solo distrófico e em solo mesotrófico no triângulo mineiro. Bioscience Journal, v. 29, n. 6, p. 2013-2029, 2013.

SILVA, J. S. Diversidade alfa, florística e fitossociologia na arie do cerradão, na APA Gama e Cabeça de Veado, DF. Dissertação de Mestrado, Instituto de Ciências Biológicas da Universidade de Brasília. 126 p, 2009.

SILVA, H. G.; FIGUEIREDO, N.; ANDRADE, G. V. Estrutura da vegetação de um cerradão e a heterogeneidade regional do Cerrado no Maranhão, Brasil. Revista Árvore, v.32, n.5, p.921-930, 2008. Disponível em: $<$ http://www.scielo.br/scielo.php?pid=S0100$67622008000500017 \&$ script=sci_abstract\&tlng=pt>. Doi: http://dx.doi.org/10.1590/S0100-67622008000500017. 